\title{
Sex in the commercial break: how bouncing speech bubbles informed the nation
}

\author{
Susan Quilliam
}

Freelance Writer, Broadcaster and Agony Aunt, Cambridge, UK

\section{Correspondence to \\ Ms Susan Quilliam; \\ susan@susanquilliam.com}

Received 16 November 2010 Accepted 18 November 2010

\section{Background}

Here's your starter for ten. Name me the most common sexually transmitted infection (STI) - the one that it just so happens is the subject of three other articles in this issue of the Journal (see pages 4, 10 and 17). Correct. Chlamydia.

But while you and I know that answer, the general public - and especially that youthful segment of the general public that is most affected by the problem often haven't had the chance to be so informed. Which is why so many under$25 \mathrm{~s}$ are at risk of chlamydia, and why so many of us sexual health professionals spend vast amounts of time hitting our heads against this particular brick wall.

Enter the Department of Health (DH) and the Central Office of Information (COI), which in the summer of 2009 decided to launch a nationwide advertising campaign to highlight sexual issues in general and chlamydia issues in particular. Enter too your intrepid reporter who, following her previous coverage of The Sex Education Show ${ }^{1}$ decided to take a similar behindthe-scenes peek into the inner workings of yet another phenomenon, this time that of behavioural change.

You'll have seen the advertising campaign, of course - it's the one with the animated bubbles and the tagline 'Worth Talking About'. With luck, you'll also have seen that chlamydia testing uptake is on the rise and chlamydia incidence is on the decline - and if you are seeing that, then credit is due. But given that long-term statistics aren't yet available, what fascinates me currently is not whether the campaign works but why and how it was born. Why did it start? How was the core concept arrived at? How were the messages developed? How was it produced? And why, why, why those animated bubbles?

\section{The start}

The original initiative came 2 years ago from the then British Government's recognition that while everyone involved in sexual health is trying very hard, we have our work cut out because of the general approach to sexuality on our sceptred isle. Cross the North Sea and attitudes in The Netherlands, for example, make the task so much easier: more openness, more discussion, more acceptance of the fact that it's fine to talk about sex, and so admit and take action on the inherent risks. If only the Brits felt the same as the Dutch.

The Government's vision was to achieve just that. They aimed not to cruelly scare nor to coldly inform, but to create a change in Britain's culture such that the nation would find it less challenging to talk about sexuality and hence easier to face and tackle the problems.

And so it was that in early summer 2009, a brief to implement this vision was drawn up by the $\mathrm{DH}$ and the COI. There were several strands to the brief, covering a variety of topics - myth-busting, communication, negotiation and contraception - and a broad age range. The specified market for the chlamydia part of the campaign was young people aged 16-25 years, a good use of the 'catch 'em young' principle, as well as a response to the fact that STI rates are rising in that particular cohort.

The call went out to a number of agencies inviting them to 'pitch' for the job and one can easily imagine hordes of eager 'creatives' hammering away in endless, coffee-driven, 2.00am brainstorming sessions throughout the summer, before finally presenting their ideas to the COI in September 2009.

\section{The core concept}

In fact, we no longer need to try to imagine this scenario, for we know precisely which team won the pitch, and happily their representative was willing to talk to me about what they did in relation to the chlamydia advertisements. The agency in 
question was VCCP, and the spokesperson in question was Kirsty Gent (Account Director).

"VCCP has done a lot of behavioural change work in the past", Kirsty told me, "including a campaign to cut down binge drinking". But as none of the team had previously worked on sexual health issues, it was wisely decided to go back to basics: getting everyone up to speed on the facts and figures; examining the previously mentioned good practice in The Netherlands; doing intensive rounds of qualitative research with the target audience; consulting teachers, social workers and sexual health organisations including the Family Planning Association (FPA). All this was, according to Kirsty, "quite an eye opener" for those involved.

So what about those adrenalin-fuelled brainstormers? There was clearly huge creativity involved, but the process Kirsty described to me also seemed fully grounded in reason. "We knew that our central idea needed to be getting people talking; we pretty soon identified 10-12 key phrases that encompassed the issue and from those 'Sex... worth talking about' clearly worked well."

"It was positive, non-judgmental, action oriented. It not only went across the different media we were using - print, web, television - but, vitally, it went across all the different markets we had to deal with: young people talking to friends about chlamydia, partners talking to each other, patients talking to health professionals."

\section{The messages}

Talking, then, was the core concept, but there were also certain key messages to be expressed about the STI itself. The team kept it very simple: by my reckoning there were just five main ideas. First, the problem: "chlamydia is the most commonly diagnosed STI", which "could stop you having kids". Second, personal involvement: "most people who catch it don't get any symptoms" so "one of us might have it without knowing". Third, the solution: "there's an easy way to find out if you've got it", which is "a chlamydia test they're offering it to everyone our age". Fourth, the reassurance: "it doesn't hurt" because "you just pee in a pot". Fifth, the call to action: "say yes to the test".

It's worth noting that each of these messages comprises an element vital to any attempt at behavioural change. A target market needs to be aware of a problem, to accept that the problem applies to them, to recognise the solution is available, to realise that anxieties about the solution are groundless, and finally to know exactly what to do in response.

How did VCCP get these messages across? The first piece of the puzzle was to have all the messages appear in some form in every part of the campaign: four print advertisements plus one television commercial and follow-up material on the Web. So the "Worth Talking About' tagline is included in every manifestation, with other elements included as text at the foot of the print advertisements and in the voiceover of the commercial; the Web address is always spelt out as a source of further information.

\section{The bubbles}

The main message carriers, however, are those famous bubbles. They convey facts, thoughts, speech and emotions, as well as being eye-catching, attention-grabbing and memorable; as such they are absolutely fit for purpose.

But, explained Kirsty, there was an additional justification for their use. Because apparently behavioural change campaigns that show real people can fail spectacularly. "Viewers can disengage if they see characters portrayed that they don't immediately identify with. They think 'this message doesn't apply to me'." Which, of course, is the very last response we would want on the issue of chlamydia, where personal responsibility is key. So, no specific characters in the advertisements then.

But how to square that need for no characters with an equal need to portray 'Talking'? The bubbles provide the answer: three-dimensional cyphers with minimal characterisation aside from the occasional pink for a girl and blue for a boy. The ultimate Rorschach test, allowing viewers through a variety of ages, genders and social backgrounds to identify and think 'this message absolutely applies to me'.

The final piece of the puzzle came via the words that lie within the bubbles. "We wanted to encourage people not to have just one 'Big Talk about Sex' but instead get them chatting about sexually related issues in everyday conversation. We wanted to remove the taboos, and also to show ideal behaviour so that people could learn from that and copy it." Hence the campaign uses ordinary language: short conversations, brief sentences, 'vernacular' words and a copious use of 'questions and answers'. [NB. In the TV advertisements, these words are also animated not only for emphasis but also for accessibility and a touch of humour. So, for example, the jiggling word 'kids' when referring to potential infertility, or the rising water to add extra weight to the expression 'pee in a pot'.]

\section{The production}

Concept and messages decided and accepted, VCCP were able to move ahead to production. The print campaign was done in four varieties, each a large still photograph aimed at one scenario (discussion between friends, discussion between partners, talking to a health professional), each set against a different background (station, cinema, surgery) and each containing one of the key messages (such as "My girlfriend wants us to have a chlamydia test... You should. It doesn't hurt or anything.") (Figures 1 and 2).

The television advertisement was first planned with storyboards, leading to a location shoot for the three scenes (cafe, park bench, bus stop), with the dialogue 


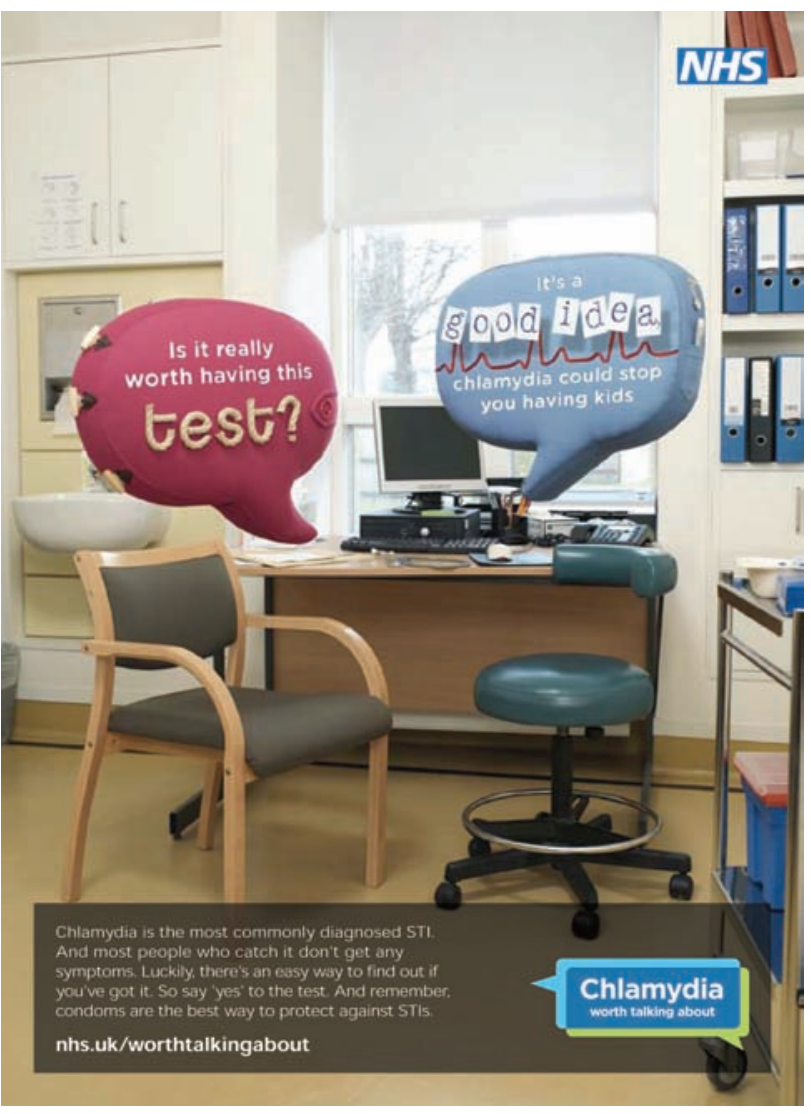

Figure 1 'Chlamydia Worth Talking About' campaign. Image from the advertising campaign showing a young woman in a general practitioner's surgery setting. OVCCP. Image kindly provided by VCCP.

for each scene recorded later by specialist voiceover artists. Once again the messages are simply expressed, such as: "How was the doctor's? Yeah, fine. He asked me if I wanted to have a chlamydia test. And did you? Yeah. They're offering it to everyone our age". The final scene is an aerial shot of a street with bubbles 'walking along', a voiceover urging "Say yes to the test".

When it came to the bubbles, VCCP didn't take the easy way out and use Photoshop ${ }^{\mathrm{TM}}$. Instead, they called in a specialist model maker, John Steed, to create dozens of bubbles each with their own motif - plain, knitted, stripy, puffa - and dozens of individual words, such as jelly letters on springs to reflect 'worry'. These bubbles were photographed separately and dropped into both the still photograph and the television scenes. [Amusingly, VCCP had originally intended to hammer home the 'No to chlamydia' message by making the word 'chlamydia' itself appear in the bubbles as "scary, dripping with tentacles and slime. But we toned this down to simply spiky after feedback”.]

\section{The lessons}

So far, so fascinating. And on one level, I feel that sheer interest in the process justifies my exploration; it is surely always a worthwhile exercise to discover

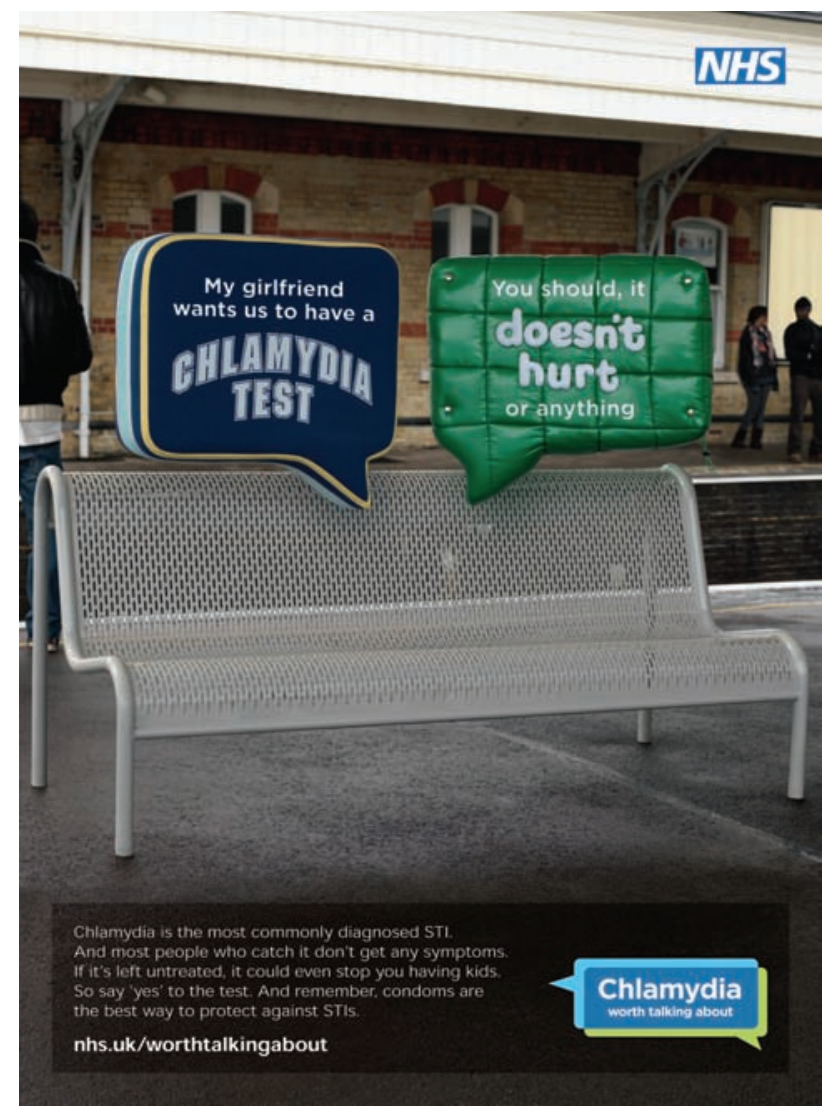

Figure 2 'Chlamydia Worth Talking About' campaign. Image from the advertising campaign showing two young men in a station setting. (OVCCP. Image kindly provided by VCCP.

"How on earth do they do that?" But I also came away with two further insights that I think hold a message for Journal readers.

The first is to take on board and consider the overall aim of the campaign. That creative strap line shouldn't remain handcuffed to whole page advertisements and commercial breaks; the thought that chlamydia (or indeed sex in general) is 'worth talking about' is crucial to everything we do, and indeed should - as the British Society for Sexual Medicine (BSSM) has recently pointed out in its guidelines on the management of sexual difficulties - be a key part of the care offered by all medical professionals, whether specialising in sexual health or not. VCCP's aim, surely, was not just to convince young people to talk sensibly about sexuality but to encourage everyone to do the same.

My second thought is that despite the fact that this campaign was not developed by experienced sex educators, the process by which it was developed is a highly useful template. VCCP talked in depth and with a listening ear to their target market. They made sure the messages they communicated were few, simple and easily understood. They ensured their audience could identify with the issues. They kept the language simple and accessible. They tried to model out ways of talking about sex easily and in everyday conversation. 
And they made the whole campaign utterly positive, non-judgmental and action-oriented. Not a bad checklist for a conversation that any of us might have with a patient, about chlamydia or about anything else for that matter.

Of course I'm preaching to the converted here, as all the above mentioned principles are what guide Journal readers daily through the commitment of our work. But I guess I came away from my investigation feeling that this campaign was not only an example of good practice in the advertising field, it was also an example of good practice in the sexual health field. In short, something that is definitely worth writing about.

Acknowledgements The author would like to thank the Department of Health, the Department for
Eduction, VCCP, and everyone involved in the making of the 'Chlamydia Worth Talking About' campaign: Mark Orbine (Creative Director), Rachael Robinson (Art Director), Dan Bryant (Copy Writer), Kirsty Gent (Account Director), John Steed (Model Maker), Stink (Production Company), Christian Bevilaqua (Director) and Trevor Ray Hart (Photographer).

Competing interests None.

Provenance and peer review Commissioned; internally peer reviewed.

\section{Reference}

1 Quilliam S. Everything you always wanted to know about... The Sex Education Show. J Fam Plann Reprod Health Care 2010;36:39-40. 